\title{
MANTLE CELL LYMPHOMA MAY HAVE A DIFFERENT CLINICAL COURSE IN MEXICAN MESTIZOS: REAL-WORLD DATA FROM A SINGLE CENTER
}

\author{
Alejandra C. Córdova-Ramírez ${ }^{1,2}$, Luisa F. Sánchez-Valledor ${ }^{1,3}$, Gerardo Colón-Otero 4 , \\ Montserrat Rivera-Alvarez ${ }^{1,2}$, Gilberto D. Elías-De-la-CruZ ${ }^{1,2}$, Iván Murrieta-Alvarez ${ }^{1,2}$, \\ Yahveth Cantero-Fortiz ${ }^{1,3}$, Andrés León-Peña ${ }^{1,6}$, Juan C. Olivares-Gazca ${ }^{1,2}$, Guillermo J. \\ Ruiz-Delgado ${ }^{1,2,5}$, AND Guillermo J. Ruiz-ArgüELles ${ }^{1,2,5}$, \\ ${ }^{1}$ Centro de Hematología y Medicina Interna de Puebla, Pue.; ${ }^{2}$ Universidad Popular Autónoma del Estado de Puebla, Pue.; \\ ${ }^{3}$ Universidad de las Américas Puebla, Pue.; ${ }^{4}$ Mayo Clinic, Jacksonville FL, USA; ${ }^{5}$ Laboratorios Ruiz, Puebla, Pue.; \\ ${ }^{6}$ Benemérita Universidad Autónoma de Puebla, Pue., Mexico
}

\begin{abstract}
Background: The biology of some hematological diseases varies among different populations. No previous studies have evaluated the clinical behavior of mantle cell lymphoma $(\mathrm{MCL})$ in México. Objective and Methods: This is a retrospective review of MCL cases seen in Mexico from January 2003 to June 2020. A total of 12 cases were identified. Results: There were nine males and three females; median age was 56 years. Eight patients had a high MCL international prognostic index score, one was intermediate, and three were low. Five patients had circulating malignant monoclonal cells. Initial treatment included rituximab, cyclophosphamide, daunorubicin, vincristine, and prednisone (R-CHOP) and CHOP. Subsequent treatment included hematopoietic stem cell transplantation in five patients; two were given maintenance therapy. Splenectomy was done in four patients. Median overall survival (OS) for all the patients has not been reached and exceeds 162 mos: OS at 162 mos was $56 \%$. Achieving a complete remission (CR) after the first treatment was a significant prognostic factor, with a median OS exceeding 141 mos in patients achieving $C R$, and 16 mos among those not achieving $C R(p=0.0006)$. Conclusion: Some of $\mathrm{MCL}$ patients in Mexico have an indolent clinical course, particularly patients who achieve a CR to initial treatment and who undergo splenectomy. (REV INVEST CLIN. 2021;73(2):94-9)
\end{abstract}

Key words: Mantle cell. Non-Hodgkin. Lymphoma. Treatment. Prognosis.

\section{INTRODUCTION}

Mantle cell lymphoma (MCL) is a rare and aggressive disease which accounts for approximately $5 \%$ of all B-cell non-Hodgkin's lymphomas $(\mathrm{NHL})^{1}$. The incidence of $M C L$ is higher in non-Hispanic Whites in the
United States 2,3 . There is very limited information about this variant of $\mathrm{NHL}$ in México ${ }^{4}$. We have previously shown that several B-cell malignancies such as chronic lymphocytic leukemia (CLL), multiple myeloma, Waldenstrom's macroglobulinemia, and others are substantially less frequent and less aggressive
*Corresponding author:

Guillermo J. Ruiz-Argüelles

E-mail: gruiz1@clinicaruiz.com
Received for publication: 29-07-2020

Approved for publication: 26-08-2020

DOI: $10.24875 / R I C .20000381$

0034-8376 / (c) 2020 Revista de Investigación Clínica. Published by Permanyer. This is an open access article under the CC BY-NC-ND license (http://creativecommons.org/licenses/by-nc-nd/4.0/). 
among Mexican patients than in Caucasian populations ${ }^{4,5}$. Here, we report a retrospective analysis of a group of 12 patients with MCL.

\section{MATERIALS AND METHODS}

\section{Patients}

The files of all the patients identified with the diagnosis of MCL after January 2003 were analyzed. Clinical evaluation of $\mathrm{MCL}$ patients included history and physical examination, assessment of performance status, comorbidities, B symptoms, features of the treatment, response to treatment, evolution, and current status.

\section{Approval}

Clínica Ruiz Institutional Review Board approved this study and every participant signed and provided a consent document before the study.

\section{Laboratory workup}

It included a complete blood cell count with differential count, comprehensive metabolic panel, lactate dehydrogenase, beta-2 microglobulin levels, hepatitis panel, HIV status, and serum immunoglobulin levels. Immunophenotype on peripheral blood looking for the typical MCL phenotype (CD5, CD20, CD19, slgM/ slgD, FMC-7 + B cells with monoclonal kappa/lambda light chains, and dim/negative CD23, dim/negative CD200, and strong cyclin D1) was done.

\section{Histological studies}

Involved tissue and bone marrow aspiration/biopsy were performed at the time of the initial diagnosis. Immunohistochemical analysis of involved nodal/extranodal tissues looking for a strong nuclear staining for cyclin D1 (BCL-1 or PRAD-1) expression on MCL cells and SOX-11 expression was done.

\section{Imaging studies}

Imaging studies were obtained for staging purposes: whole-body positron emission tomography-computed tomography (CT) scan or computerized tomography (CT).

\section{Statistical analysis}

The primary outcome measure was overall survival (OS), defined as the time elapsed between the diagnosis of $\mathrm{MCL}$ and death from any cause, with censoring of patients who were alive on the last follow-up date. Secondary outcome measure was complete remission (CR), defined as the absence of adenomegaly, splenomegaly, and monoclonal B cell in the peripheral blood. Differences were assessed with Fisher's exact test. OS was estimated by the Kaplan-Meier method and differences between groups with compared with the log-rank test 6 . Two-sided $p<0.05$ was considered as statistically significant. All statistical analyses were carried out in Stata 14 (StataCorp, College Station, TX).

\section{RESULTS}

\section{Patients}

Nine males and three females were included; median age was 56 years (range 40-87). Eight patients had a high $\mathrm{MCL}$ international prognostic index (MIPI) score, one was intermediate, and three were low. Five patients had circulating malignant monoclonal cells (Table 1).

\section{Treatment patterns}

Five patients were treated initially with rituximab, cyclophosphamide, daunorubicin, vincristine, and prednisone (R-CHOP) and two with $\mathrm{CHOP}$; three were given subsequently bortezomib with or without thalidomide or lenalidomide; and one patient was given bendamustine. In four patients, splenectomy was performed: the removed spleens weighed 1.4, 1.8, 2.8, and $4 \mathrm{~kg}$. Five patients were given hematopoietic stem cell transplantation (HSCT): three allogeneic and two autologous (Table 1). No patients were treated with ibrutinib, acalabrutinib, obinutuzumab, temsirolimus, idelalisib nor venetoclax.

\section{Survival}

Patients have been followed for a median of 44 mos (range 0.6-162). Median OS for all the patients has not been reached and exceeds 162 months, whereas the OS at 162 months is $56 \%$ (Fig. 1). The 5 -year OS 
Table 1 . Salient features of the 12 patients with $\mathrm{MCL}$

\begin{tabular}{|c|c|c|c|c|c|c|c|c|c|c|c|c|}
\hline & 1 & 2 & 3 & 4 & 5 & 6 & 7 & 8 & 9 & 10 & 11 & 12 \\
\hline Age & 60 & 56 & 56 & 87 & 49 & 46 & 67 & 48 & 49 & 49 & 51 & 61 \\
\hline Sex & $\mathrm{F}$ & $M$ & $M$ & $\mathrm{~F}$ & $M$ & $M$ & $\mathrm{~F}$ & $M$ & $M$ & $M$ & $M$ & $M$ \\
\hline Site & Nodal & Spleen & $\begin{array}{l}\text { Bone } \\
\text { Marrow }\end{array}$ & Nodal & Nodal & $\begin{array}{l}\text { Bone } \\
\text { marrow }\end{array}$ & $\begin{array}{l}\text { Bone } \\
\text { marrow }\end{array}$ & $\begin{array}{l}\text { Bone } \\
\text { marrow }\end{array}$ & Nodal & $\begin{array}{l}\text { Bone } \\
\text { marrow }\end{array}$ & $\begin{array}{l}\text { Bone } \\
\text { marrow }\end{array}$ & Nodal \\
\hline Leukemia & No & Yes & No & No & No & No & Yes & No & Yes & Yes & No & No \\
\hline MIPI & High & High & Intermediate & High & High & Low & High & Low & Low & Low & Low & High \\
\hline $\mathrm{R}-\mathrm{CHOP}$ & No & No & Yes & No & Yes & No & No & No & No & Yes & Yes & Yes \\
\hline CHOP & Yes & No & No & No & No & No & No & No & Yes & No & No & No \\
\hline Others & Bleo & No & Bort & PDN & Thal & $\begin{array}{l}\text { Thal, } \\
\text { bort, } \\
\text { dexa }\end{array}$ & $\mathrm{R}$, benda & $\begin{array}{l}\text { Hyper- } \\
\text { CVAD, } \\
\text { R, MTX, } \\
\text { Ara-C }\end{array}$ & No & No & No & No \\
\hline Splenectomy & No & Yes & No & No & No & Yes & No & No & Yes & Yes & No & No \\
\hline HSCT & Auto & Allo & No & No & No & Auto & Allo & - & Allo & - & - & -- \\
\hline Remission & Yes & Yes & No & No & Yes & Yes & Yes & Yes & No & Yes & Yes & Yes \\
\hline $\begin{array}{l}\text { Survival time } \\
\text { (months) }\end{array}$ & 12.7 & 13.5 & 0.05 & 0.24 & 1.9 & 5.7 & 4 & 1 & 2.5 & 11.8 & 6.4 & 3.8 \\
\hline Status & Alive & Alive & Alive & Dead & Alive & Alive & Aliver & Alive & Dead & Alive & Dead & Dead \\
\hline
\end{tabular}

F: female; M: male; MIPI: mantle cell lymphoma international prognostic index; R-CHOP: rituximab, cyclophosphamide, adriamycin, vincristine, and prednisone; Bort: bortezomib; Thal: thalidomide; Dexa: dexamethasone; Benda: bendamustine, MTX: methotrexate, Ara-C: cytarabine; HSCT: hematopoietic stem cell transplantation; Auto: autologous; Allo: allogeneic, Time: months after the diagnosis of the lymphoma. $\mathrm{MCL}$ : mantle cell lymphoma.

Figure 1. Overall survival of the 12 patients with mantle cell lymphoma.

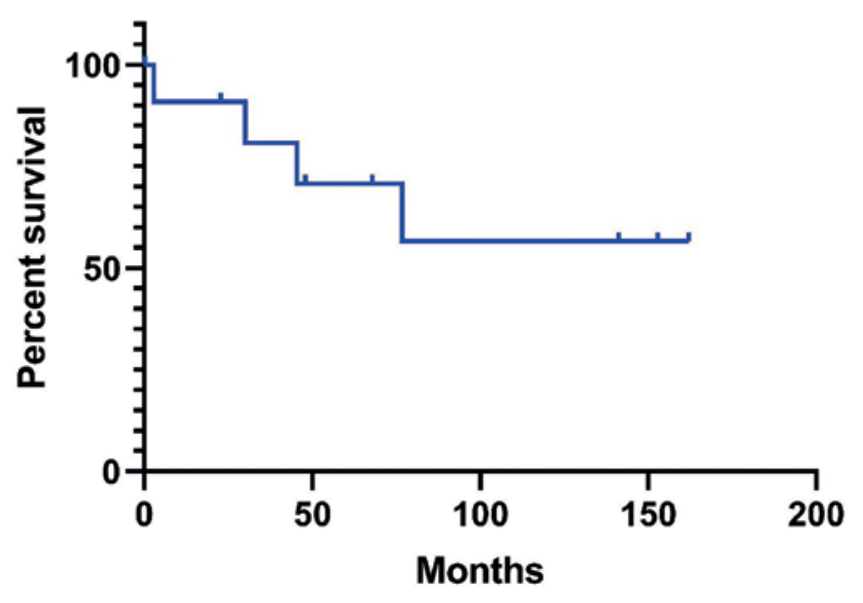

for patients with high or low MIPI scores was 60 and $83 \%$, respectively ( $p=0.91$ ), whereas the 5 -year OS of patients given or not HSCT was 51 versus $83 \%$ ( $p=0.69$, Fig. 2 ). The median OS for patients having their spleen removed was better than that of non-splenectomized patients (>162 vs. 77 months, $p=0.55$, Fig. 3 ), whereas the median OS of patients with or without a leukemic pattern of the disease was $>162$ months versus 77 months ( $p=0.35$ ). Achieving a CR after the initial treatment was a significant prognostic factor: patients who achieved it had a median OS exceeding 141 months, whereas those who did not achieve it had a median OS of 16 months $(p=0.0006)$. 
Figure 2. A) Overall survival of the 12 patients with mantle cell lymphoma, given or not hematopoietic stem cell transplants. Differences are not statistically significant $(p=0.36)$. B) Overall survival of the 12 patients with mantle cell lymphoma, having the spleen removed or not. Differences are not statistically significant $(p=0.36)$.

\section{A}
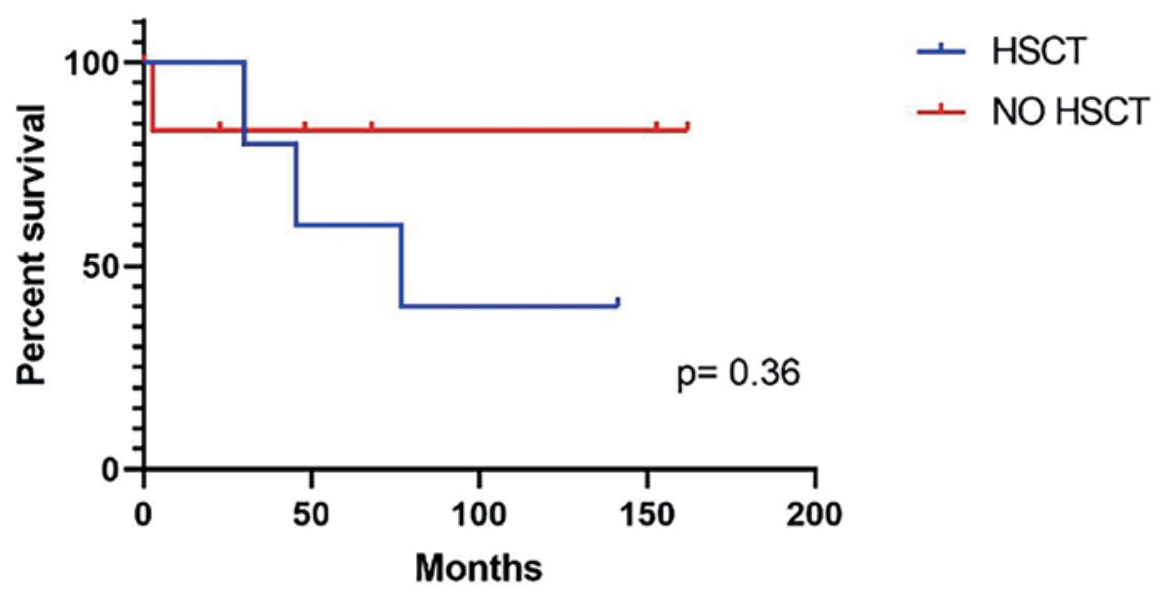

B

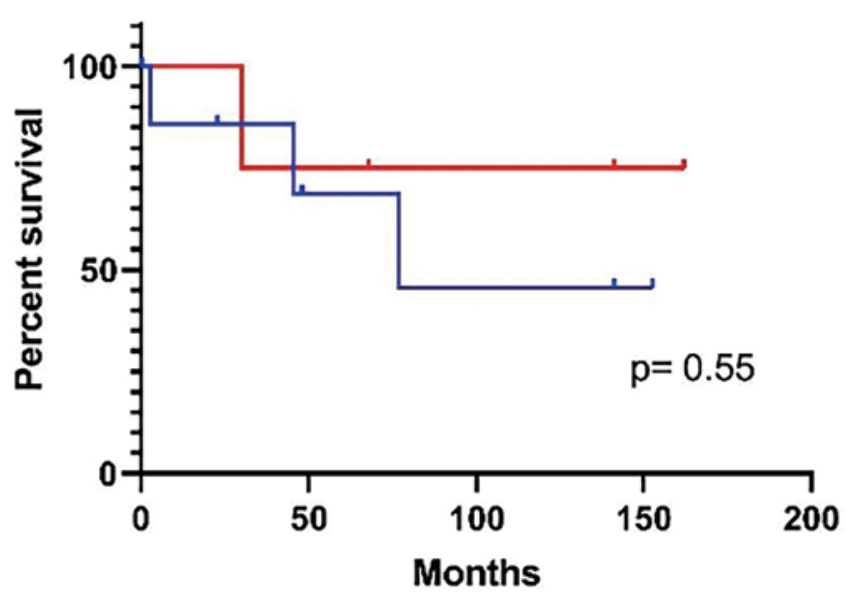

\section{DISCUSSION}

Jean Bernard, an icon in the world's hematology, presented in 1963 the concept of "geographic hematology" distinguishing two major branches; the so-called "ethnic hematology" that dealt with differences between populations and a second branch about environmental factors such as food habits, infections, and its implication with the hematological diseases referred as "environmental hematology"4,7. Along this line, we have analyzed the salient features of several hematological diseases, making comparisons with the features of some conditions in other populations ${ }^{4}$ : we have shown that two B-cell malignancies, both CLL and multiple myeloma, are less frequent and less aggressive in México than in Caucasian populations ${ }^{4,8,9}$.
Different from other chronic mature B-cell malignancies, MCL seems to be in Mexican Mestizos as frequent as in Caucasians: Carballo-Zárate et al. ${ }^{5}$ have shown that $\mathrm{MCL}$ represents in México $6.7 \%$ of all $\mathrm{B}$ cell $\mathrm{NHL}$, a figure similar to that informed from the United States, which is around $5 \%^{1,2}$. As far as the prognosis is concerned, we found that outcomes are substantially better than those informed in the literature both in Caucasian individuals ${ }^{3}$ and Taiwanese patients ${ }^{10}$, and could suggest that MCL has a more benign course in Mexican mestizos. Almost half of patients with $\mathrm{MCL}$ presented with leukocytosis, and a third, with splenomegaly; these cases resembled CLL but the immunophenotype of the clonal circulating malignant cells disclosed the true nature of the malignant B-cell proliferation; patients with a leukemic form of the disease 
Figure 3. A) Overall survival of the 12 patients with mantle cell lymphoma, having or not malignant monoclonal cell in the peripheral blood. Differences are not statistically significant $(p=0.35)$. B) Overall survival of the 12 patients with mantle cell lymphoma who achieved or not a complete remission. Differences are statistically significant $(p=0.0006)$.

A

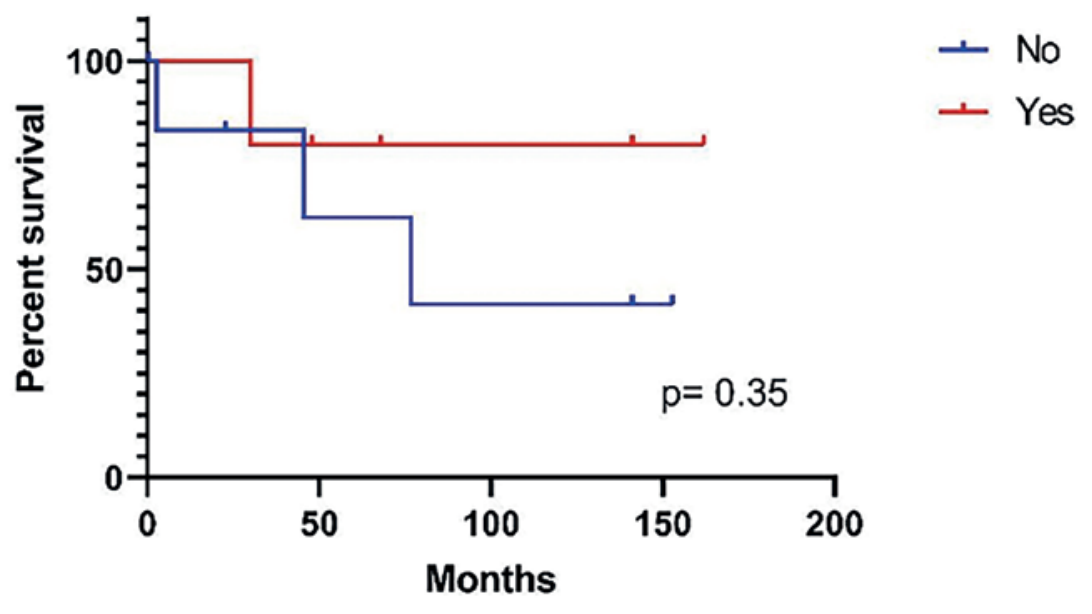

B

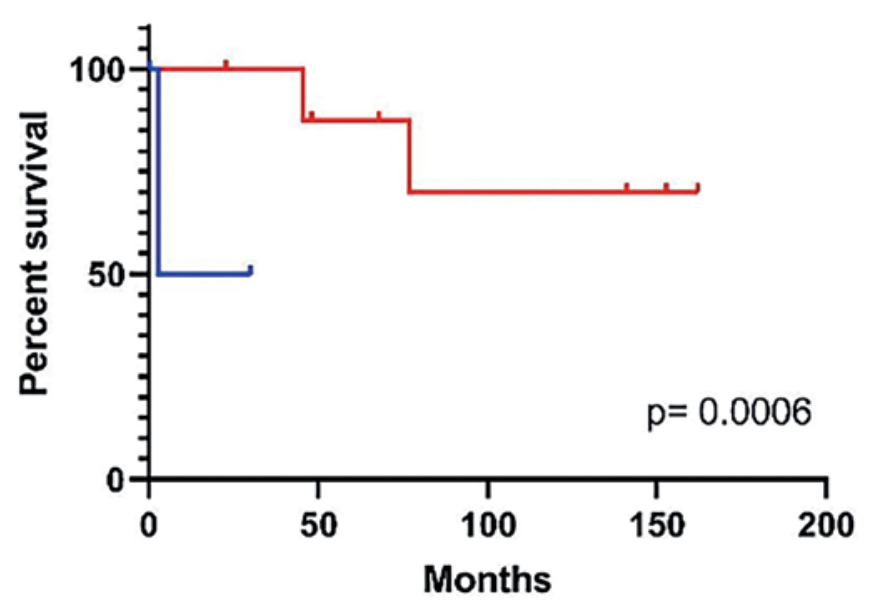

had a worse prognosis. In four cases, the spleen was removed and it is interesting to point that the OS of splenectomized patients was better than that of the non-splenectomized patients, thus supporting a role of splenectomy in the treatment of $M C L$, as it had been previously recommended ${ }^{11}$, a procedure not even considered in the current therapeutic recommendations ${ }^{3}$. It is also noteworthy that achieving a CR was a significant prognostic factor since patients who achieved it had a median OS exceeding 141 months, whereas those who did not were significantly lower. The OS of patients who were grafted was worse than that of those who did not receive a transplant; this may reflect the fact that grafted patients had more aggressive forms of the disease (Fig. 2).

This study has several drawbacks: it is retrospective, includes a small number of patients and the treatment of the patients was non-randomly assigned. This small analysis of data on MCL treated at a single institution in Mexico, suggests that some of $\mathrm{MCL}$ patients in Mexico have an indolent clinical course with median survivals that exceed 10 years, particularly in patients who achieve a CR to initial treatment and who undergo splenectomy as part of their treatment program. Additional studies are needed to either ratify or rectify these observations. 


\section{REFERENCES}

1. Monga A, Garside J, Quigley J, Hudson M, O'Donovan P, O'Rourke J, et al. Systematic literature review of the global burden of illness of mantle cell lymphoma. Curr Med Res Opin. 2020;36:843-52.

2. Wang Y, Ma S. Racial differences in mantle cell lymphoma in the United States. BMC Cancer. 2014;14:764.

3. Jain P, Wang M. Mantle cell lymphoma: 2019 update on the diagnosis, pathogenesis, prognostication, and management. Am J Hematol. 2019;94:710-25.

4. Colunga-Pedraza PR, Gómez-Cruz GB, Colunga-Pedraza JE, RuizArgüelles GJ. Geographic hematology: some observations in Mexico. Acta Haematol. 2018;140:114-20.

5. Carballo-Zárate A, García-Horton A, Palma-Berre L, RamosSalazar P, Sánchez-Verín-Lucio R, Valenzuela-Tamariz J, et al. Distribution of lymphomas in Mexico: a multicenter descriptive study. J Hematopathol. 2018;11:99-105.

6. Schemper M, Smith TL. A note on quantifying follow-up in studies of failure time. Control Clin Trials. 1996;17:343-6.
7. De Braekeleer M, De Braekeleer E, Douet-Guilbert N Geographic/ethnic variability of chromosomal and molecular abnormalities in leukemia. Expert Rev Anticancer Ther. 2015;15 1093-102.

8. Cruz-Mora A, Murrieta-Alvarez I, Olivares-Gazca JC, León-Peña A, Cantero-Fortiz Y, García-Navarrete YI, et al. Up to half of patients diagnosed with chronic lymphocytic leukemia in México may not require treatment. Haematology. 2020;25:156-9.

9. Murrieta-Alvarez I, Steensma DP, Olivares-Gazca JC, OlivaresGazca M, León-Peña A, Cantero-Fortiz Y, et al. Treatment of persons with multiple myeloma in underprivileged circumstances: real-world data from a single institution. Acta Haematol. 2020;11:1-7.

10. Wang YH, Yu SC, Ko BS, Yang YT, Yao M, Tang JL, et al Correlative analysis of overall survival with clinical characteristics in 127 patients with mantle cell lymphoma: a multi-institutional cohort in Taiwan. Int J Hematol. 2020;112:385-94.

11. Ruchlemer R, Wotherspoon, AC, Thompson JN, Swansbury JG Matutes E, Catovsky D. Splenectomy in mantle cell lymphoma with leukaemia: a comparison with chronic lymphocytic leukaemia. Br J Haematol. 2002;118:952-8. 